\title{
Morphological and cellular basis for airflow limitation in smokers
}

\author{
M. Saetta*, R. Finkelstein**, M.G. Cosio**
}

Morphological and cellular basis for airflow limitation in smokers. M. Saetta, R. Finkelstein, M.G. Cosio. CERS Journals Ltd 1994.

ABSTRACT: Airflow limitation has two well-defined components, increased resistance, which is found predominantly in the small airways, and loss of elastic recoil.

Small airways contribute to the increased resistance to flow by the narrowing of the airway lumen. Morphometric studies have shown that smokers have increased epithelial abnormalities, cellular inflammatory infiltrates in the airway wall, increased muscle and fibrosis, when compared with nonsmokers. Along with these anatomical changes, an increased percentage of airways $<400 \mu \mathrm{m}$ in diameter is found. In addition to the measured changes, other nonmeasurable, dynamic events occur in the airways of smokers, which further decrease lumen diameter. There is ample evidence to show that the airways of smokers react to nonspecific stimuli by constricting, which results in increased resistance and decreased forced expiratory volume in one second $\left(\mathrm{FEV}_{1}\right)$. The pathological changes found in smokers, that could be responsible for active muscle constriction and airway narrowing include: 1) airway epithelial damage, resulting in increased permeability and impairment of other epithelial function; 2) chronic airway inflammation; 3) structural changes in the airway wall; and 4) loss of alveolar attachments.

However, not all smokers develop the abovementioned airway abnormalities. We describe how smokers could develop either centrilobular emphysema (CLE), or panlobular emphysema (PLE). We have found that smokers with CLE have more abnormal and narrower small airways, and flow limitation is correlated with the small airway abnormalities and not with loss of recoil. In contrast, smokers with PLE have much less severe airway abnormalities, diffuse emphysema that can be detected microscopically at a stage when $F E V_{1}$ might be only mildly abnormal, and early changes in elastic recoil as evidenced by the changes in the pressure-volume curve of the lung. Furthermore, in PLE, airflow limitation is correlated with loss of recoil but not with abnormalities in the small airways.

We believe that the mechanisms involved in the pathogenesis of the two types of emphysema in smokers are different; an airborne mechanism for CLE, possibly related to airway hyperresponsiveness, and a bloodborne mechanism for PLE, which may be related to dysfunction of $\alpha_{1}$-antiproteases. We conclude that the separation of smokers based on their emphysema type is essential if we are to understand the pathogenesis of chronic obstructive pulmonary disease (COPD) in these subjects.

Eur Respir J., 1994, 7, 1505-1515.
*Institute of Occupational Medicine, University of Padova, Padova, Italy. **Respiratory Division, Royal Victoria Hospital \& McGill University, Montreal, Quebec, Canada.

Correspondence: M.G. Cosio

Respiratory Division

Room L411

Royal Victoria Hospital

687 Pine Avenue West

Montreal

Quebec

Canada

H3A $1 \mathrm{~A} 1$

Keywords: Airway hyperresponsiveness airway inflammation

airflow limitation

bronchiolitis

emphysema

Received: February 71994

Accepted after revision June 211994

MGC was supported by the Medical Research Council of Canada and The Network Centres of Excellence, Canada.
The pathological hallmarks of chronic obstructive pulmonary disease (COPD) are inflammation of the small airways (bronchiolitis) and destruction of lung parenchyma (emphysema). The functional consequence of these abnormalities is airflow limitation.

As flow is the result of a driving pressure (elastic recoil) and of an opposing resistance (airway patency), it is best to refer to the changes in flow seen in smokers as airflow limitation, rather than airflow obstruction, since both loss of elastic recoil and increase in airway resistance play an important role in the observed decrease in flow. The bronchiolitis will contribute to airflow limitation by narrowing and obliterating the lumen and by actively constricting the airway. On the other hand, emphysema, by reducing the elastic recoil of the lung through parenchymal destruction and increase in alveolar size, as well as by reducing the elastic load applied to the airways through destruction of alveolar attachments, will also contribute to the airflow limitation characteristic of smokers. Although there is increasing evidence that the large airways are inflamed in patients with COPD, they are not believed to contribute directly to the airflow limitation in these patients.

In this review, we will emphasize the measurable (morphometric) abnormalities of the airways as well as the nonmeasurable (dynamic) events occurring in vivo contributing to the airflow limitation in smokers and their relation to parenchymal destruction-emphysema. 


\section{The small airways: morphology-function correlations}

\section{Small airway abnormalities in "normal" smokers}

By using the retrograde catheter technique, MACKLEM and MEAD [1] demonstrated that, contrary to previous beliefs, the airways $<2 \mathrm{~mm}$ in diameter (small airways) contributed to no more than one quarter of the total airway resistance in dog lungs. HogG et al. [2] found, with the same technique, that in excised normal lungs only $25 \%$ of the total airways resistance was contributed by airways $<2-3 \mathrm{~mm}$ in diameter. However, in smokers with mild emphysema, there was a fourfold increase in peripheral airway resistance, whilst total airway resistance remained unchanged. More severe degrees of emphysema resulted in a marked increase in total airway resistance, due almost entirely to the increase in the peripheral airway component. This work established the then new, and still prevailing, concept that peripheral airways are the major site of increased resistance in smoke-induced obstructive lung disease.

NiEwOEHNER et al. [3] were first to show that definite pathological abnormalities could already be present in the peripheral airways of young smokers. This observation, along with the findings of HoGG et al. [2] that the site of airflow limitation in smokers is found in the small airways, created an enthusiasm for tests of small airway function which was based on the notion that these tests could become abnormal before flow limitation (changes in forced expiratory volume in one second $\left(\mathrm{FEV}_{1}\right)$ ) was obvious, and hence could identify the smoker most likely to progress to chronic airflow limitation.

By studying smokers who had tests of pulmonary function (including those reflecting the small airways) before undergoing resection for lung tumours, investigators at McGill University [4] developed a pathological score to describe the microscopic changes in the small airways of smokers, in order to study the correlations between the morphology and the function. Specifically, they scored luminal occlusion, goblet-cell metaplasia, squamous-cell metaplasia, mucosal ulcers, muscle hypertrophy, inflammatory cell infiltrate, fibrosis, and pigment deposition of the airway wall in airways smaller than $2 \mathrm{~mm}$ in diameter. This study showed that these patients had similar but much more extensive abnormalities in the small airways than those described by NiEwOEHNER et al. [3], probably due to the fact that the patients studied at McGill University were older, had smoked more, and had some degree of COPD. The first abnormalities that could be seen in the older smokers were changes in the epithelium with squamous metaplasia, and a chronic inflammatory infiltrate with a slight increase in the connective tissue in the walls of the small airways [4]. As the pathological and functional abnormalities progressed, the cellular inflammatory infiltrate changed little, but there was a progressive increase in the connective tissue pigment and muscle in the airway wall. Significant goblet cell metaplasia could be seen in the most severely affected airways.

When the physiological measurements reflecting small airway abnormalities, such as nitrogen wash-out test, volume of isoflow, maximal mid-expiratory flow and other function tests, e.g. the forced expiratory volume in one second as percentage of forced vital capacity $\left(\mathrm{FEV}_{1} / \mathrm{FVC}\right)$, mid flow rate and residual volume were compared with the pathological score, all measurements showed a progressive deterioration as the score for the morphological abnormalities increased; however, only the group with the most severe small airway score had a substantial degree of emphysema. The striking correlation between the progression of physiological impairment and the degree of small airway disease suggested that inflammatory changes of the small airways made an important contribution to the functional deterioration seen in COPD, even in the presence of emphysema. Furthermore, in subjects with normal $\mathrm{FEV}_{1} / \mathrm{FVC}$ ratio, two tests of small airway function, the slope of phase III of the nitrogen wash-out and the volume of isoflow of the air-helium flow-volume loops, were able to detect mild abnormalities of the small airways at a time when other spirometric tests were normal [4].

Other investigators later confirmed these findings using lungs obtained either at surgery or autopsy. BEREND and co-workers [5] showed that the tests of small airway function correlated best with the total pathology score of the small airways and, in particular, with the inflammatory score. They also found that the closing volume and the mid-expiratory flow correlated significantly with a measure of airway luminal size [6]. In another study, performing maximal expiratory flowvolume curves in excised human lungs, BEREND and coworkers [7] showed that flow in the trachea correlated significantly with the total pathology score of the small airways as well as the inflammation, fibrosis and emphysema scores. PETTY et al. [8] performed lung function tests in lungs obtained at autopsy. The lungs were divided into two groups on the basis of a normal or abnormal closing capacity, and the study demonstrated higher total pathology, inflammation and fibrosis scores in the lungs with higher closing capacity. WRIGHT et al. [9] also examined the morphological basis of small airway obstruction in a group of smokers who underwent lung resection. When the $\mathrm{FEV}_{1}$ was normal, an increasing number of abnormal tests of small airway function, such as volume of isoflow, closing volume as a percentage of vital capacity, and slope of phase III of the single-breath nitrogen wash-out were associated with increasingly severe fibrosis scores in membranous bronchioles and with worsening intraluminal and mural inflammatory scores of respiratory bronchioles (respiratory bronchiolitis).

Taken together, these studies demonstrate that cigarette smoke can elicit an inflammatory reaction in the membranous and respiratory bronchioles early in life, and this abnormality can be detected by tests of small airway function, such as slope of phase III of the nitrogen wash-out. However, these early pathological and physiological abnormalities do not progress in all smokers, and the tests designed to detect the early physiological abnormalities in the small airways do not predict the $15-20 \%$ of smokers who progress to chronic airflow limitation [10]. 
Once the pathological changes in the airways are established, the striking correlation between the progression of physiological impairment and the degree of small airway disease suggests that inflammation of the small airways makes an important contribution to the functional deterioration seen in COPD, even in the presence of emphysema.

\section{Small airway changes in established COPD}

Many other studies have addressed the pathological changes of the small airways in smokers and their relationship to the flow limitation found in COPD. Cosio et al. [11] compared abnormalities in the small airways in smokers and nonsmokers dying accidentally. Pulmonary function status was not known; however, the degree both of macroscopic and microscopic emphysema, assessed by the mean linear intercept which measures the airspace enlargement, was not different in smokers and nonsmokers, suggesting that in most cases the effects of cigarettes were mild. Nonetheless, abnormalities in the membranous and respiratory bronchioles of smokers were quite apparent, showing increased goblet cells, cellular inflammatory infiltrates, muscle and respiratory bronchiolitis when compared with nonsmokers. The overall mean diameter of airways $<2 \mathrm{~mm}$ was similar in both groups, but smokers had a significantly greater proportion of bronchioles smaller than $400 \mu \mathrm{m}$ than nonsmokers, and this proportion was closely related to the total score of airway abnormalities. Several other studies have indicated that airflow limitation has a better relationship with the proportion of very narrowed airways of 200 and $350 \mu \mathrm{m}$ diameter $[8,12,13]$. Of special interest, this marked narrowing may also be associated with hypoxaemia and right ventricular hypertrophy $[12$, 14-16].

HaLE et al. [17] extended the study of Cosio et al. [11] by adding another group of 18 lungs of patients dying with known and measured COPD. This study is of interest, since it clearly shows the progression of the small airway pathological changes from nonsmoking older individuals to smokers with mild disease and finally to smokers dying with COPD. The cellular inflammatory infiltrate, fibrosis, and muscle in the airway wall progressed significantly in a stepwise fashion in the three groups and, as expected from the initial study by Cosio et al. [11], the number of airways $<400 \mu \mathrm{m}$ increased accordingly. The mean diameter of the small airways tended to decrease, but the range of diameters was so large that no statistical differences could be found even between patients with the most severe COPD and nonsmokers. A similarly wide range was found in all the airway inflammatory abnormalities measured in the two groups of smokers, indicating that not every smoker reacts in the same fashion to cigarette smoke; thus, suggesting that some smokers are more prone to develop small airway abnormalities than others. Not surprisingly, smokers dying of COPD had more emphysema in their lungs than nonsmokers and patients with mild disease. The degree of emphysema assessed macroscopically correlated with all abnormalities found in the small airways. With this large degree of intercorrelation, it is not surprising that in severe COPD, the degree of emphysema might override correlations between morphology of the small airways and function. Nonetheless, HaLE et al. [17] found that the degree of airflow limitation correlated not only with emphysema but also with the average airway diameter and the proportion of airways smaller than $400 \mu \mathrm{m}$, a function of the total pathological score of the small airways.

Similar results were obtained by NAGAI and co-workers [18] in patients dying with COPD. In their study, flow rates antemortem correlated with the degree of macroscopic emphysema, but also with the proportion of airways smaller than $400 \mu \mathrm{m}$ in diameter and the degree of deformity of bronchioles. They interpreted these findings as decreases in flow being secondary both to emphysema, causing loss of elastic recoil, and to airway abnormalities. It was also clear from their study that for the same degree of airflow limitation, smokers with lesser amounts of emphysema had more diseased small air-ways, again pointing towards the combined effect of loss of recoil secondary to emphysema and increase in airways resistance secondary to small airway abnormalities in the production of the airflow limitation in COPD.

\section{Pathophysiology of lung destruction - emphysema}

\section{Centrilobular (CLE) and panlobular emphysema (PLE) in smokers}

An important component of the definition of emphysema is the destruction of alveolar walls, which can be detected microscopically even in smokers without evidence of airspace enlargement, i.e. in smokers with normal values of mean linear intercept [19]. The microscopic measurement of this parenchymal destruction (destructive index (DI)) can, therefore, allow an early identification of the disease, at a time when emphysema is not detectable macroscopically. The functional significance of this early destruction is demonstrated by the correlation with indices of airflow limitation and loss of elastic recoil of the lung [19].

Lung destruction is evenly distributed in panlobular emphysema and it is mainly localized in the centre of the lobule in centrilobular emphysema. Physiological evidence suggesting that smokers could develop two different types of lung destruction was provided by EIDELMAN et al. [20]. They found that smokers with COPD had different patterns of functional abnormalities.

Some exhibited pressure-volume curves typical of emphysema and resembled those seen in $\alpha_{1}$-antiprotease deficiency, with high compliance and low elastic recoil pressure at high lung volumes. About one half of their subjects had low or normal compliance and, despite similar elastic recoil, had lower $\mathrm{FEV}_{1}$ and pressure-volume curves nontypical for emphysema.

Based on these findings, KIM et al. [21] reasoned that such dissimilar functional behaviour ought to correspond 
to different parenchymal morphological abnormalities: panlobular emphysema for the smokers with mechanical characteristics similar to $\alpha_{1}$-antiprotease deficiency, and centrilobular emphysema for the others. They tested this hypothesis in 34 patients undergoing lung resection who had pulmonary function tests performed before surgery. Emphysema was assessed microscopically, characterized as centrilobular or panlobular using available definitions, and quantified using the mean linear intercept. Both types of emphysema could be found in this population of smokers, 18 patients had centrilobular emphysema and 16 had panlobular emphysema. Mechanical properties were found to be different in the two types of emphysema. Patients with panlobular emphysema had a higher compliance and a higher constant of elasticity $(\mathrm{K})$ than patients with centrilobular emphysema. As the emphysema worsened, compliance, $\mathrm{K}$ and the elastic recoil at $90 \%$ of total lung capacity worsened in panlobular emphysema but did not change in centrilobular emphysema. Furthermore, losses of elasticity correlated significantly with the extent of emphysema in lungs with panlobular emphysema but not in centrilobular emphysema. These findings suggest that mechanical properties are different in the two types of emphysema, and these differences become more marked with the progression of the airspace enlargement, suggesting that the two types of lung destruction are different from the start.

\section{Small airway abnormalities in centrilobular emphysema and panlobular emphysema}

Another important difference between the two types of emphysema is the extent of airway abnormalities. Lungs with centrilobular emphysema had higher total pathological scores of the small airways than lungs with panlobular emphysema, mainly ascribable to increased muscle and fibrosis in the airway wall. Probably as a result of the more severe pathological involvement, lungs with centrilobular emphysema had more airways smaller than $400 \mu \mathrm{m}$ in diameter than lungs with panlobular emphysema. Not surprisingly, the pathophysiology of flow limitation in smokers, a function of airway resistance and elastic recoil pressures, differs between the two types of emphysema. Flow was shown to decrease as airway abnormalities increased in centrilobular emphysema, but no relationship between flow and airway disease could be found in panlobular emphysema. In contrast, flow decreases significantly as elasticity decreases in panlobular emphysema but not in centrilobular emphysema. Some patients with centrilobular emphysema exhibited decreased flow with normal or even increased elastic recoil pressures; whereas, in those with panlobular emphysema flow limitation was always accompanied by loss of recoil. These findings clarify the pathogenesis of airflow limitation in smokers, indicating that in centrilobular emphysema it is primarily a function of airway abnormalities with elastic recoil loss playing an additive role. By contrast, in patients with panlobular emphysema, the flow limitation seems to be mainly a function of reduced elastic recoil (fig. 1).

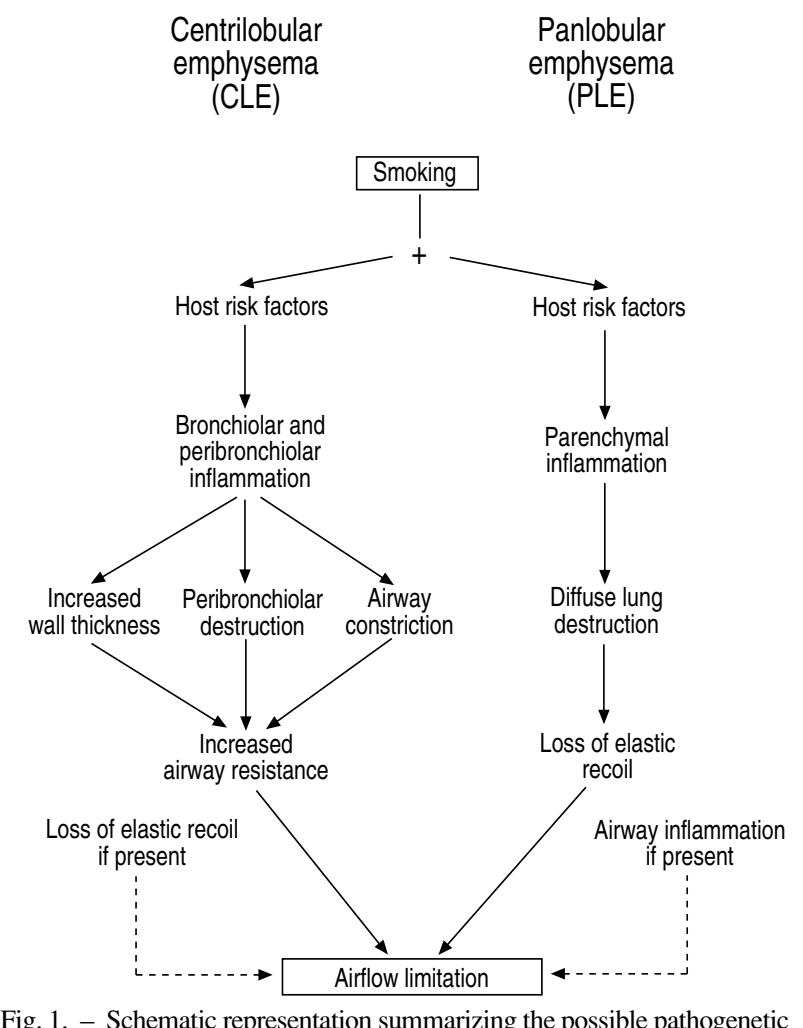

Fig. 1. - Schematic representation summarizing the possible pathogenetic mechanisms of airflow limitation in smokers.

SAETTA and co-workers [22] have extended the observations of Кім et al. [21] by precisely assessing the extent of lung involvement by either type of emphysema in smokers. They found that the centrilobular and panlobular emphysemas can be present in pure form or may overlap each other, and that, even in the mixed forms, one type of emphysema is always clearly predominant. The type of emphysema present and its extent had important consequences on the degree of airway abnormalities and on the mechanical properties of the lung. Indeed the pathological score for airway abnormalities was highest in the pure centrilobular lungs and decreased in a stepwise fashion as the amount of panlobular emphysema increased. By contrast, lung compliance was highest in panlobular lungs and decreased as the amount of centrilobular emphysema increased.

Among smokers, the severity of small airway disease correlates with the extent of centrilobular emphysema. There is also a definite tendency for small airways in the upper lung to be more diseased than those in the lower lung, a topographical distribution that corresponds to centrilobular emphysema [11]. It is also known that disease in the small airways temporally precedes centrilobular emphysema [4], and that emphysema lesions first appear in the respiratory bronchiole, where the inflammatory reaction, particularly macrophage accumulation, is most intense [3, 4, 23]. We believe these various observations are complimentary and support the hypothesis that small airway disease is causally related to the development of centrilobular emphysema. LEOPOLD and Gough [24] also showed that the small airways were usually inflamed in lungs with centrilobular emphysema but in contrast seldom 
in patients with predominant panlobular emphysema. Similar observations were reported by ANDERSON and FORAKER [25], who felt that centrilobular emphysema and panlobular emphysema were two different diseases.

These studies are of interest, because they not only clarify the mechanisms of airflow limitation and the role of the bronchioles in COPD, but confirm the possibility of smokers developing two diseases with different pathogenetic mechanisms. The diffuse destruction seen in panlobular emphysema might result from a bloodborne mechanism. On the other hand, the uneven pattern of lung destruction seen in centrilobular emphysema is associated with more severe abnormalities in the small airways, suggesting that centrilobular destruction is related to airborne factors and intimately related to the airway inflammatory process. In favour of this hypothesis are the findings of SAETTA and co-workers [22], who investigated the relationship between the inflammation of the small airways and the extent of parenchymal destruction using the destructive index (DI; [19]) in the lungs of smokers with centrilobular and those with panlobular emphysema. In lungs with centrilobular emphysema a close correlation between the inflammation of the airways and the parenchymal destruction was evident. This correlation was not present in lungs with panlobular emphysema. Thus, it is likely that the inflammatory reaction seen in and around small airways and respiratory bronchioles spreads centrifugally to the parenchyma surrounding these airways and eventually destroys the alveolar walls attached to the airways, the respiratory bronchioles and alveolar ducts. The preservation of alveolar structure and size with concomitant destruction of alveolar ducts and respiratory bronchioles in centrilobular emphysema would be in favour of this possibility.

These studies set a new basis for the investigation of lung disease in smokers. If the intimal pathogenetic mechanisms in the two types of emphysema in smokers are different, as the evidence suggests, the study of cigarette-induced lung disease as a single entity will further delay the understanding of COPD.

\section{Role of airway inflammation in the limitation of airflow}

There is ample evidence demonstrating that the airways of smokers react to nonspecific stimuli by constricting, and this constriction results in increased resistance and decreased $\mathrm{FEV}_{1}$. Many authors [26-32] believe that smokers might have hyperreactive airways, and that this hyperreactivity might contribute to the natural history of COPD. Others [33, 34] believe the contrary, that the hyperresponsiveness found in smokers is a consequence of the already decreased airway dimensions and lower $\mathrm{FEV}_{1}$. However, recent longitudinal studies by RIJCKEN and co-workers [35] have shown that hyperresponsiveness precedes the decline in lung function in smokers, emphasizing that the behaviour of the bronchial muscle in some individuals will make them prone to loss of lung function when exposed to cigarette smoke. Regardless of whether hyperresponsiveness is primary or secondary to airway geometry, there is sufficient evidence indicating that airways of smokers constrict when exposed to nonspecific stimuli, and that smokers constrict more than ex-smokers and nonsmokers. The severity of hyperresponsiveness in smokers is of a lesser degree than in asthma, probably because the abnormal conditions of the airway smooth muscle and atopy, that are the basis for the hyperresponsiveness in asthmatics, are not present in most smokers with COPD. However, the abnormalities found in the airways of smokers could contribute to the constriction of a normal airway muscle. Hence, regardless of the presence or lack of muscle hyperresponsiveness, muscle constriction in smokers is probably an important component of airflow limitation in COPD.

A number of pathological changes could be responsible for active muscle constriction and airway narrowing in COPD. These include: 1) airway epithelial damage resulting in increased epithelial permeability and impairment of other epithelial functions; 2) chronic airway inflammation; 3) structural changes in the airway wall; and 4) loss of alveolar attachments. The role of the epithelium and inflammation may be the key to the pathogenesis of airway narrowing. Most of the knowledge in this area is derived from animal work, and has been linked with the pathogenesis, inflammation and airway constriction of asthma. However, in many respects this could also apply to COPD.

\section{Airway epithelial damage}

The protective barrier formed by the airway epithelium is altered by cigarette smoke. Denuded epithelium, mucosal ulcers and goblet and squamous metaplasia are consistently found in airways of smokers. Numerous studies have shown that cigarette smoke causes airway epithelium to become more permeable to electron-dense tracers with damage to junctional complexes [36-39]. The altered epithelium permeability leaves underlying afferent nerve endings and irritant receptors exposed to bronchoconstrictor and other proinflammatory substances. Thus, the dysfunction of the epithelial cells could contribute to bronchoconstriction and airway inflammation. Finally, altered integrity of the epithelial barrier permits access of plasma exudate to the airway lumen and also has mechanical and inflammatory effects on the small airway.

Once across the epithelial barrier, plasma exudate and its associated macromolecules, immediately fill the interstices between epithelium projections [40]. Liquidfilled interstices could amplify the degree of luminal compromise in at least two ways. Firstly, luminal crosssectional area is reduced as the interstices fill with fluid [41]. Secondly, plasma proteins could alter the surface tension of the airway lining fluid, which can further compromise the airway lumen by producing points of instability and closure of the airways [42].

Airway epithelium has the potential to contribute to the development of airway inflammation through different mechanisms. One possible mechanism is the recruitment and activation of neutrophils, through the 15-lipoxygenase 
pathway, by airway epithelial cells [43-47]. Another system implicated in airway inflammatory responses, which could be triggered by the alteration of the epithelial surface, is the sensory nerves. Nonadrenergic, noncholinergic sensory nerve fibres, present in the airway epithelium, smooth muscle and blood vessels, release tachykinins, including substance $\mathrm{P}$, neurokinin $\mathrm{A}$ and neurokinin B. Stimulation of these nerves causes a constellation of responses known as neurogenic inflammation, which includes airway mucous secretion, increased airway microvascular permeability, exudation of plasma into the airway lumen [48-51], contraction of smooth muscle in vitro [52-54], interactions with mast cells [55, 56], chemotaxis and adhesion of neutrophils in the airway circulation $[57,58]$, activation of monocytes to release inflammatory cytokines, such as interleukin-6, and degranulation of eosinophils which can further damage airway epithelium [59, 60]. An increased number of eosinophils has recently been reported in bronchial biopsies of nonatopic smokers with symptoms of chronic bronchitis $[61,62]$, indicating that airway eosinophilia is not an exclusive characteristic of asthma, but may also be present in chronic bronchitis.

The inflammatory effects of the tachykinins are, in part, controlled by neutral endopeptidase, an enzyme that binds to the surface of the specific cells that are the site of action to tachykinins and cleaves and inactivates them. Neutral endopeptidase activity is found specifically in epithelium, glands, nerves and smooth muscle [63]. The abolition of neutral endopeptidase activity by stripping the epithelium or by inhibition of this enzyme by specific inhibitors is known to increase smooth muscle responses to bronchoconstrictor substances [64]. If airway epithelium is shed or altered, any effects of tachykinins may be more pronounced, not only on airway smooth muscle, but also on the mucosa and submucosa

Respiratory epithelium seems to modulate directly the responsiveness of bronchial smooth muscle by the release of inhibitory factors for smooth muscle contraction. In fact, the respiratory epithelium has a high density of $\beta$ adrenoreceptors, higher than bronchial smooth muscle [65]. The increased smooth muscle relaxation in response to isoprotorenol in bronchial rings with intact epithelium compared with preparations denuded of epithelium highlights the importance of the $\beta$-adrenoreceptors in the epithelial smooth muscle interaction [66]. Furthermore, removal of the epithelium in canine bronchial rings increases the contractile responses evoked by acetylcholine, histamine and 5-hydroxytryptamine [67]. Thus, the absence of epithelial cells potentiates the reactivity of the underlying smooth muscle. These mechanisms seem to be modulated by inhibitory factors released by the epithelial cells. These factors have been identified [68], although their exact nature is unknown. Interestingly, the airway mucus may inactivate these factors [69].

In summary, the integrity of the epithelial surface seems to be necessary for the normal function and regulation of the airways. Loss of the epithelium and/or possible replacement of normal epithelial ciliated cells by goblet or squamous cells might be one of the initial events in the development of an inflammatory reaction and airway narrowing in smokers. Albeit small, the chronicity of the stimulation could perpetuate the process and enhance the progress of the pathological changes in smokers.

\section{Chronic airway inflammation}

Most of the studies of small airways in smokers have analysed the inflammation of the airways in a quantitative fashion. Qualitative morphometric studies are much fewer. This is an area badly in need of study, since a better understanding of the inflammatory process is the clue to the unveiling of the pathogenesis of this disease. In the previous section, we reviewed how injury to the epithelium, the first structure encountered by cigarette smoke, could promote and perpetuate an inflammatory reaction in the airway. There is ample evidence that inflammatory cells and their mediators are key elements in the development of disease in general and of the airways in particular. A myriad of cell components and mediators have been described with the potential to maintain inflammation, recruit other inflammatory or effector cells, and produce bronchoconstriction.

Inflammation per se may be responsible for mild airflow limitation [4, 8, 69], and it has been suggested that inflammation may lead to functional bronchiolar constriction by releasing mediators of inflammation that may act directly on bronchiolar smooth muscle [70]. The chronicity of inflammation would, in turn, produce other changes, such as fibrosis of the airway, and could possibly increase the smooth muscle either directly as a result of inflammation or indirectly as a result of chronically increased muscle tone. These changes, by increasing the thickness of the airway wall, will promote airway narrowing and airflow limitation. Finally, inflammation of the airways could play an important role in the destruction of the alveolar walls attached to the airways, and this loss of alveolar attachments would further contribute to airflow limitation by deforming and narrowing the airway lumen.

Neutrophils. Neutrophils are prominent in the small airways of smokers, and their numbers correlate significantly to the amount of cigarettes smoked [71]. In animal studies, exposure to cigarette smoke and other irritants promotes neutrophils to appear promptly in the airways.

The mechanism by which cigarette smoke causes neutrophil accumulation remains speculative, but several possibilities can be postulated. Cigarette smoke causes alveolar macrophages, which are found abundantly in the respiratory bronchioles of smokers, to release chemotactic factors which recruit neutrophils [72]. Components of cigarette smoke, such as nicotine, have been found to be chemotactic for human neutrophils, although they do not affect degranulation or superoxide production [73]. Absorbed constituents of smoke could alter endothelial cells or neutrophils directly, or the adherence of neutrophils to endothelium. Adhesion of neutrophils to vascular endothelial cells is critical for recruitment of these cells from the circulation to inflammatory tissue sites. This adhesion requires specific interactions between neutrophil 
surface glycoproteins, including the beta ${ }_{2}$-class of integrins (CD11/CD18), and endothelial cell surface proteins, including intercellular adhesion molecule-1 (ICAM-1) and endothelial-leucocyte adhesion molecule-1 (ELAM1) [74-79]. It is believed that epithelium derived ICAM1 dependent neutrophil-epithelial cell adhesion plays an important role in the pathophysiology of inflammatory airway disease. Cox et al. [80] showed that bronchial epithelial cells markedly increase the survival of human neutrophils in vitro via the release of granulocyte colonystimulating factor (GM-CSF) and granulocyte-macrophage colony-stimulating factor (GM-CSF), indicating that epithelial cells could modulate the cellularity of the inflammatory response in the acute phase of the smoker injury, whilst the epithelial cell layer is still intact.

The traditional belief that the neutrophil is the key cell in the pathogenesis of emphysema should be reassessed. Our own studies [81] have shown that the number of total cells in the alveolar wall are directly related to the degree of lung destruction measured by DI. However, neutrophils were inversely related to DI, suggesting that other cells might be involved in the destruction of the lung. Moreover, Wright [82] found neutrophils to be present in the airway wall tissue, independent of the presence or absence of emphysema. Thus, the role of the neutrophil in the development of emphysema is not clear and other possible mechanisms ought to be explored.

Lymphocytes: In the large airways of smokers with chronic bronchitis an increased number of T-lymphocytes has been found in comparison with nonsmoking controls [83, 84]. Increased numbers of cells expressing interleukin-2 receptor (a marker of recent activation) and of cells expressing very late activation antigen-1 (a marker of chronic activation) have also been demonstrated in these subjects [84]. The simultaneous presence of both activation markers suggests the presence of T-lymphocytes at different stages of activation in chronic bronchitis. Interestingly, an increased number of activated T-lymphocytes in the large airways is also a characteristic feature of bronchial asthma, indicating a morphological similarity between these two inflammatory diseases.

One study has examined the presence of lymphocytes in the small airway of smokers. Bosken et al. [71] measured B-lymphocytes and T-lymphocytes in the airways of smokers with and without airflow obstruction. The number of B-lymphocytes in the entire wall and the adventitia accounted for about $15 \%$ of the total inflammatory cells, and it was the only cell type statistically increased in numbers in the airways of smokers with obstruction when compared with those without airflow obstruction.

Much remains to be learned about the inflammation of the small airways in smokers. Available results are of interest and point towards a possible alteration in the lymphocyte regulation in smokers that might be initiated locally in the lung and eventually be detected in the blood, at least in heavy smokers [85-89]. The study of lymphocyte inflammation in the small airways and its relationship to the inflammation of the parenchyma might give some clues about the mechanisms of lung destruction in these subjects.

The function of the lymphocyte infiltration in the lung of smokers is not known. However, it is known that lymphocytes play an important role in the inflammatory response. Lymphokines produced by activated T-cells, such as interferon-gamma (IFN- $\gamma$ ), interleukin-4 (IL-4), interleukin-5 (IL-5), and GM-CSF, are key mediators in the cellular immune response [90-91]. They are active in the control of many other cellular lines, such as eosinophils, neutrophils, mast cells and monocytes, and are able to activate and degranulate these effector cells [91]. Furthermore, CD4+ and CD8+ lymphocytes are key cells in the regulation of B-lymphocytes and in the cell-mediated and humoral immune systems; and, finally, lymphocytes may play an important role in the pathogenesis of emphysema in subjects with alpha ${ }_{1}$-antiprotease deficiency [92-96].

In this respect, recent findings from our laboratory are of interest [97]. In a series of 21 lungs obtained surgically, we have found that the number of T-lymphocytes $\cdot \mathrm{mm}^{-3}$ of lung tissue correlated strongly with the degree of microscopic emphysema, whilst a negative correlation was found between the number of neutrophils and lymphocytes. Furthermore, the numbers of neutrophils and lymphocytes were negatively correlated, suggesting that as long as the inflammation in the lung is acute (neutrophil predominant) there is no emphysema. However, when the inflammation becomes lymphocytic, emphysema appears and is related to the load of T-lymphocytes. These findings may open new avenues to the pathogenesis of lung destruction in smokers.

\section{Structural changes in the airway wall}

Several reports $[4,9,98]$ have shown that as obstruction worsens so does the airway fibrosis and this, along with the inflammatory infiltrate, will contribute to increase the thickness of the airway wall and to decrease the airway lumen. Muscle in the airway wall is also increased in smokers when compared with nonsmokers [11], and it worsens as the airflow decreases further [17, 99]. Of interest are the findings of KIM et al. [21] who reported that smokers with centrilobular emphysema had significantly more muscle in the small airways than smokers with panlobular emphysema, even though the inflammatory infiltrate was quantitatively similar in both. Furthermore, for the same $\mathrm{FEV}_{1}$, smokers with centrilobular emphysema are more reactive to methacholine than smokers with panlobular emphysema [100]. Thus, muscle is increased in smokers, is able to constrict and at times to hyperreact, and it will passively contribute to increase airway wall thickness.

Both the walls, internal and external to the smooth muscle layer, are thicker in smokers with airflow limitation than in smokers without airflow limitation, and increasing thickness is associated with smaller airway diameters [101]. The effect of such thickening is not only to decrease the airway lumen, but also to alter the mechanical behaviour of the small airways. MoReno et al. [102] elegantly showed that, as the muscle constricts, 
the thickness of the wall increases and encroaches on the lumen, in such a way that the thicker the airway wall internal to the muscle the greater the narrowing resulting from a given degree of smooth muscle shortening.

Wall thickness and fibrosis are not only confined to the internal part of the airway but also external to the smooth muscle layer [102]. The mechanical effects of fibrosis and increased airway wall thickness external to airway smooth muscle are different from those of increased thickness of the internal wall. The data of Gunst et al. [103] suggest that in normal airways the forces of lung elastic recoil provide an elastic afterload to peripheral airway smooth muscle, and impede its ability to shorten. This elastic load increases as lung volume and recoil increase. According to the interdependence theory, the pressure applied to the outer surface of intrapulmonary airways is equal to the sum of forces applied to the outer surface of the airway by the attached alveolar walls expressed as a fraction of the external surface area of the airway. As the airway wall thickens, the attached alveolar walls become shorter, the forces on the airway wall decrease, the outer airway surface area increases and, hence, the pressure applied to the airway decreases. MACKLEM [104] has postulated that the thickening external to the smooth muscle can influence the relationship between smooth muscle contraction and airway narrowing by uncoupling the lung's elastic recoil forces from the airway smooth muscle, allowing it to shorten excessively.

\section{Loss of alveolar attachments}

It would seem logical to speculate that loss of the alveolar support around the airways ought to have an important effect on the patency of the small airways and, consequently, on the lung function, if it were to occur in smokers.

ANDERSON and FORAKER [105] were the first to link pulmonary parenchymal and small airway disease in smokers. They postulated that inflammation of the small airways extends to the parenchyma, leading to weakening and destruction of the alveolar walls; this loss of alveolar attachments to bronchiolar walls then leads to a reduction in the calibre of the airways because of loss of radial traction forces. SAETTA and co-workers [106] tested this hypothesis and, indeed, demonstrated that the inflammation of the small airway walls correlated closely with the destruction of alveolar attachments in smokers. Furthermore, when compared to nonsmokers, smokers had fewer intact alveolar attachments for any particular diameter of small airways. Functionally, the loss of alveolar attachments was found to correlate significantly with loss of elastic recoil, increase in closing volume and decrease in $\mathrm{FEV}_{1}$ [106, 107]. NAGAI and co-workers [108] examined lungs obtained at autopsy from patients with moderate to severe chronic airflow obstruction and emphysema, and found that the loss of normal alveolar attachments was closely related to emphysema. The deformity index, used to describe the irregularity in shape and deformity of peripheral airways, was related to the loss of alveolar attachments and to the decreases in flow in these patients. Thus, it seems apparent that emphysematous changes around the airways will significantly interact with airway patency in the production of airflow limitation.

\section{Conclusion}

The role of the pathological changes of small airways in the airflow limitation in COPD and their relationship to parenchymal destruction is complex, and goes far beyond morphometric measurements of pathological score and luminal sizes.

Increasing evidence suggests that dynamic events constantly triggered by cigarette smoking can accentuate narrowing and promote a chronic inflammatory process, resulting in thicker, inflamed, deformed and narrow airways with emphysematous changes around them. Possibly alteration of the epithelium is the initial event after the first few cigarette puffs. We have described how the epithelium can initiate and maintain the inflammatory process in the airway wall and at the same time constrict the otherwise normal airway muscle. The neutrophil is probably first recruited in the airways; however, it seems that eventually alteration of the T-cell subsets ensues. Similar events may take place in the lung parenchyma, and evidence is appearing which casts doubt about the role of neutrophils and supports the role of mononuclear cells in the pathogenesis of lung destruction [81].

Following the airway inflammatory process, fibrosis of the wall then occurs, with increase in wall thickness that would accentuate the airway narrowing produced by muscle constriction. The inflammatory process seems to migrate centrifugally towards the parenchyma, destroying it and increasing airway narrowing even further. It is probable that these mechanisms play an important role in centrilobular emphysema, and that the uncontrolled inflammatory process in the membranous and respiratory bronchioles is eventually responsible for the centrilobular destruction of the lung and for the airflow limitation observed in this form of emphysema. By contrast, in panlobular emphysema, airflow limitation seems to be due mainly to loss of recoil and to have little relation to airway abnormalities (fig. 1). We can conclude that the separation of smokers based on their emphysema type is essential for a better understanding of the pathogenesis of airflow limitation in these subjects.

\section{References}

1. Macklem PT, Mead J. Resistance of central and peripheral airways measured by a retrograde catheter. J Appl Physiol 1968; 22: 395-401.

2. Hogg JC, Macklem PT, Thurlbeck WM. Site and nature of airway obstruction in chronic obstructive lung disease. N Engl J Med 1968; 278: 1355-1360.

3. Niewoehner DE, Kleinerman J, Rice DB. Pathologic changes in the peripheral airways of young cigarette smokers. N Engl J Med 1974; 291: 755-758. 
4. Cosio M, Ghezzo H, Hogg JC, et al. The relations between structural changes in small airways and pulmonary function tests. N Engl J Med 1978; 298: $1277-$ 1281.

5. Berend N, Wright JL, Thurlbeck WM, Marlin GE, Woolcock AJ. Small airways disease: reproducibility of measurements and correlation with lung function. Chest 1981; 79: 263-268.

6. Berend N, Woolcock AJ, Marlin GE. Correlation between the function and structure of the lung in smokers. Am Rev Respir Dis 1979; 119: 695-705.

7. Berend N, Skoog C, Thurlbeck WM. Single-breath nitrogen test in excised human lungs. J Appl Physiol: Respirat Environ Exercise Physiol 1981; 51: 1568-1573.

8. Petty TL, Silvers GW, Stanford RE, Baird MD, Mitchell RS. Small airway pathology is related to increased closing capacity and abnormal slope of phase III in excised human lungs. Am Rev Respir Dis 1980; 121: 449-456.

9. Wright JL, Lawson LM, Paré PD, Kennedy S, Wiggs B, Hogg JC. The detection of small airways disease. Am Rev Respir Dis 1984; 129: 989-994.

10. Buist AS, Vollmer WM, Johnson LR, McCamant LE. Does the single-breath $\mathrm{N}_{2}$ test identify the smoker who will develop chronic airflow limitation? Am Rev Respir Dis 1988; 137: 293-301.

11. Cosio MG, Hale KA, Niewoehner DE. Morphologic and morphometric effects of prolonged cigarette smoking on the small airways. Am Rev Respir Dis 1980; 122: 265-271.

12. Bignon J, Khoury F, Even P, Andre J, Brouet G. Morphometric study in chronic obstructive bronchopulmonary disease. Pathologic, clinical, and physiologic correlations. Am Rev Respir Dis 1969; 99: 669-695.

13. Matsuba K, Thurlbeck WM. The number and dimensions of small airways in emphysematous lungs. Am J Pathol 1972; 67: 265-276.

14. Bignon J, Andre-Bougeran J, Brouet G. Parenchymal, bronchiolar and bronchial measurements in centrilobular emphysema. Relation to weight of right ventricle. Thorax 1970; 25: 556-567.

15. Jamal K, Fleetham JA, Thurlbeck WM. Cor pulmonale: correlations with central airway lesions, peripheral airway lesions, emphysema and control of breathing. Am Rev Respir Dis 1990; 141: 1172-1177.

16. Nagai A, West WW, Thurlbeck WM. The National Institutes of Health Intermittent Positive-Pressure Breathing trial: pathology studies. II. Correlation between morphologic findings, clinical findings, and evidence of expiratory airflow obstruction. Am Rev Respir Dis 1985; 132; 946-953.

17. Hale KA, Ewing SL, Gosnell BA, Niewoehner DB. Lung disease in long-term cigarette smokers with and without chronic airflow obstruction. Am Rev Respir Dis 1984; 130: 718-721.

18. Nagai A, West WW, Paul JL, Thurlbeck WM. The National Institutes of Health Intermittent Positive-Pressure Breathing trial: pathology studies. I. Interrelationship between morphologic lesions. Am Rev Respir Dis 1985; 132: 937-945.

19. Saetta M, Shiner RJ, Angus GE, et al. Destructive index (DI): a measurement of lung parenchymal destruction in smokers. Am Rev Respir Dis 1985; 131: 764-769.

20. Eidelman DH, Ghezzo H, Kim WD, Hyatt RE, Cosio MG. Pressure-volume curves in smokers. Comparison with alpha ${ }_{1}$-antitrypsin deficiency. Am Rev Respir Dis 1989; 139: 1452-1458.

21. Kim WD, Eidelman DH, Izquierdo JL, Ghezzo H, Saetta
MP, Cosio MG. Centrilobular and panlobular emphysema in smokers. Two distinct morphologic and functional entities. Am Rev Respir Dis 1991; 144: 1385-1390.

22. Saetta M, Kim WD, Izquierdo JL, Ghezzo H, Cosio MG. Extent of centrilobular and panacinar emphysema in smokers' lungs: pathological and mechanical implications. Eur Respir J 1994; 7: 664-671.

23. McLaughlin RF, Tueller EF. Anatomic and histologic changes of early emphysema. Chest 1971; 59: 592599.

24. Leopold JC, Gough J. The centrilobular form of hypertrophic emphysema and its relation to chronic bronchitis. Thorax 1957; 12: 219-225.

25. Anderson AE, Foraker AG. Centrilobular emphysema and panlobular emphysema: two different diseases. Thorax 1973; 27: 547-550.

26. Ramsdale EH, Morris MM, Roberts RS, Hargreave FE. Bronchial responsiveness to methacholine in chronic bronchitis: relationship to airflow obstruction and cold air responsiveness. Thorax 1984; 39: 912-918.

27. Yan K, Salome CM, Woolcock AJ. Prevalence and nature of bronchial hyperresponsiveness in subjects with chronic obstructive pulmonary disease. Am Rev Respir Dis 1985; 132: 25-29.

28. Arnup ME, Mendella LA, Anthonisen NR. Effects of cold air hyperpnea in patients with chronic obstructive lung disease. Am Rev Respir Dis 1983; 128: 236-239.

29. Benson MK. Bronchial responsiveness to inhaled histamine and isoprenaline in patients with airway obstruction. Thorax 1978; 33: 211-213.

30. Woolcock AJ, Peat JK, Salome CM, et al. Prevalence of bronchial hyperresponsiveness and asthma in a rural adult population. Thorax 1987; 42: 361-368.

31. Welty C, Weiss ST, Tager IB, et al. The relationship of airways responsiveness to cold air, cigarette smoking and atopy to respiratory symptoms and pulmonary function in adults. Am Rev Respir Dis 1984; 130: 198203.

32. Sparrow D, O'Connor G, Colton T, Barry CL, Weiss ST. The relationship of nonspecific bronchial responsiveness to the occurrence of respiratory symptoms and decreased levels of pulmonary function. The normative aging study. Am Rev Respir Dis 1987; 135: 1255-1260.

33. Van der Lende R, Visser BF, Wever-Hess J, de Vries K, Orce NGM. Distribution of histamine threshold values in a random population. Rev Inst Hyg Mines 1973; 28: 186-190.

34. Rijcken B, Schouten JP, Weiss ST, Speizer FE, Van der Lende R. The relationship between airway responsiveness to histamine and pulmonary function level in a random population sample. Am Rev Respir Dis 1988; 137: 826-832.

35. Rijcken B, Schouten JP, Weiss ST, Rosner B, De Vries $\mathrm{K}$, Van der Lende R. Long-term variability of bronchial responsiveness to histamine in a random population sample of adults. Am Rev Respir Dis 1993; 148: 944-949.

36. Simani IAS, Inove S, Hogg JC. Penetration of the respiratory epithelium of guinea-pigs following exposure to cigarette smoke. Lab Invest 1974; 31: 75-87.

37. Boucher RC, Johnston J, Inove S, Hulbert W, Hogg JC. The effect of cigarette smoke on the permeability of guinea-pig airways. Lab Invest 1980; 43: 94-100.

38. Walker DC, Mackenzie A, Hulbert WC, Hogg JC. Cigarette smoke exposure and tight junctions of the epithelial cells of guinea-pig trachea. Am Rev Respir Dis 1982; 125(Suppl.): 264.

39. Jones JG, Lawler P, Crawley JCW, Minty BD, Hulands 
G, Veall N. Increased alveolar epithelial permeability in cigarette smokers. Lancet 1980; i: 66-68.

40. Yager D, Shore S, Drazen JM. Airway luminal liquid. Sources and role as an amplifier of bronchoconstriction. Am Rev Respir Dis 1991; 143: S52-S54.

41. Yager D, Butler JP, Bastacky J, Israel E, Smith G, Drazen JM. Amplification of airway constriction due to liquidfilling of airway interstices. J Appl Physiol 1989; 66: 2873-2884.

42. Macklem PT, Proctor DF, Hogg JC. The stability of peripheral airways. Respir Physiol 1970; 8: 191-203.

43. Hunter JA, Finkbeiner WE, Nadel JA, Goetzl EJ, Holtzman MJ. Predominant generation of 15-lipoxygenase metabolites of arachidonic acid by epithelial cells from human trachea. Proc Natl Acad Sci USA 1985; 82: 4633-4637.

44. Kirsch CM, Sigal E, Djokic TD, Graf PD, Nadel JA. An in vivo chemotaxis assay in the dog trachea: evidence for chemotactic activity of 8,15-diHETE. $J$ Appl Physiol 1988; 64: 1792-1795.

45. Goetzl EJ, Phillips MJ, Gold WM. Stimulus specificity of the generation of leukotrienes by dog mastocytoma cells. J Exp Med 1983; 158: 731-737.

46. Serhan CN, Nicolaou KC, Webber SE, et al. Sterochemistry and biosynthesis. J Biol Chem 1986; 261: 16340-16345.

47. Dahlen S-E, Raud J, Serhan CN, Bjork J, Samuelsson B. Biological activities of lipoxin A include lung strip contraction and dilation of arterioles in vivo. Acta Physiol Scand 1987; 130: 643-647.

48. Lundberg JM, Saria A, Brodin E, Rosell S, Folkers R. A substance $P$ antagonist inhibits vagally-induced increase in vascular permeability and bronchial smooth muscle contraction in the guinea-pig. Proc Natl Acad Sci USA 1983; 80: 1120-1124.

49. Coles SJ, Neill KH, Reid LM. Potent stimulation of glycoprotein secretion in canine trachea by substance P. J Appl Physiol: Respirat Environ Exercise Physiol 1984; 57: 1323-1327.

50. Rogers DF, Awvdkij B, Barnes PJ. Effects of tachykinins on mucus secretion in human bronchi in vitro Eur J Pharmacol 1989; 174: 283-286.

51. McCormack DG, Salonen RO, Barnes PJ. Effect of sensory neuropeptides on canine bronchial and pulmonary vessels in vitro. Life Sci 1989; 45: 2405-2412.

52. Carstairs JR, Barnes PJ. Autoradiographic mapping of substance $\mathrm{P}$ receptors in the lung. Eur J Pharmacol 1986; 127: 295-296.

53. Martling C-R, Theordorsson-Norheim E, Lundberg JM. Occurrence and effects of multiple tachykinins: substance $\mathrm{P}$, neurokinin $\mathrm{A}$, neuropeptide $\mathrm{K}$ in human lower airways. Life Sci 1987; 40: 1633-1643.

54. Joos G, Pauwels R, van der Straeten M. Effect of inhaled substance $\mathrm{P}$ and neurokinin $\mathrm{A}$ on the airways of normal and asthmatic subjects. Thorax 1987; 42: 779-783.

55. Joos GF, Pauwels RA, van der Straeten ME. Mechanism of tachykinin-induced bronchoconstriction in the rat. Am Rev Respir Dis 1988; 137: 1038-1044.

56. Joos GF, Pauwels RA, van der Straeten ME. The effect of nedocromil sodium on the bronchoconstrictor effect of neurokinin A in subjects with asthma. J Allergy Clin Immunol 1989; 83: 663-668.

57. McDonald DM. Respiratory tract infections increase susceptibility to neurogenic inflammation in the rat trachea. Am Rev Respir Dis 1988; 137: 1432-1440.

58. Marasco WA, Showell HJ, Beeker EL. Substance P binds to formylpeptide chemotaxis receptor on the rabbit neutrophil. Biochem Biophys Res Commun 1981; 99: 1065-1072.

59. Kroegel C, Giembycz MA, Barnes PJ. Characterization of eosinophil cell activation by peptides. Differential effects of substance P, melittin and FMET-Leu-Phe. $J$ Immunol 1990; 145: 2581-2587.

60. Lotz M, Vaughan JH, Carson DM. Effect of neuropeptides on production of inflammatory cytokines by human monocytes. Science 1988; 241: 1218-1221.

61. Saetta M, Di Stefano A, Maestrelli P, et al. Airway eosinophilia in chronic bronchitis during exacerbations. Am J Respir Crit Care Med (in press).

62. Lacoste JY, Bousquet J, Chanez P, et al. Eosinophilic and neutrophilic inflammation in asthma, chronic bronchitis and chronic obstructive pulmonary disease. $J$ Allergy Clin Immunol 1993; 92: 537-548.

63. Johnson AR, Ashton J, Schultz WW, Erdos EG. Neutral metalloendopeptidases in human lung tissue and cultured cells. Am Rev Respir Dis 1985; 132: 564-568.

64. Frossard N, Rhoden KJ, Barnes PJ. Influence of epithelium on guinea-pig airway responses to tachykinins: role of endopeptidase and cyclo-oxygenase. J Pharmacol Exp Ther 1989; 248: 292-298.

65. Xue Q-F, Maurer R, Engel G. Selective distribution of beta- and alpha ${ }_{1}$-adrenoreceptors in rat lung visualized by autoradiography. Arch Int Pharmacodyn Ther 1983; 266: 308-314.

66. Holroyde MC. The influence of epithelium on the responsiveness of guinea-pig isolated trachea. $\mathrm{Br} \mathrm{J}$ Pharmacol 1986; 87: 501-507.

67. Flavahan NA, Aarhus LL, Rimele TJ, Vanhoutte PM. Respiratory epithelium inhibits bronchial smooth muscle tone. J Appl Physiol 1985; 58: 834-838.

68. Flavahan NA, Vanhoutte PM. The respiratory epithelium releases a smooth muscle relaxing factor. Chest 1985; 87(Suppl.): 189S-190S.

69. Vanhoutte PM. Airway epithelium and bronchial reactivity. Can J Physiol Pharmacol 1987; 65: 448-450.

70. Berend N. Lobar distribution of bronchiolar inflammation in emphysema. Am Rev Respir Dis 1981; 124: 218-220.

71. Bosken CH, Hards J, Gatter K, Hogg JC. Characterization of the inflammatory reaction in the peripheral airways of cigarette smokers using immunocytochemistry. Am Rev Respir Dis 1992; 145: 911-917.

72. Hunninghake GW, Crystal RG. Cigarette smoking and lung destruction. Accumulation of neutrophils in the lungs of cigarette smokers. Am Rev Respir Dis 1983; 128: 833-838.

73. Totti N, McCusker KT, Campbell EJ, Griffin GL, Senior RM. Nicotine is chemotactic for neutrophils and enhances neutrophil responsiveness to chemotactic peptides. Science 1984; 223: 169-171.

74. Tosi MF, Stark JM, Smith CW, Hamedani A, Gruenert DC, Infeld MD. Induction of ICAM-1 expression on human airway epithelial cells by inflammatory cytokines: effects on neutrophil-epithelial cell adhesion. Am J Respir Cell Mol Biol 1992; 7: 214-221.

75. Smith CW, Marlin SD, Rothlein R, Toman C, Anderson DC. Co-operative interactions of LFA-1 and Mac-1 with intercellular adhesion molecule- 1 in facilitating adherence and transendothelial migration of human neutrophils in vitro. J Clin Invest 1989; 83: 2008-2017.

76. Smith CW. Molecular determinants of neutrophil adhesion. Am J Respir Cell Mol Biol 1990; 2: 487-489.

77. Lo SK, Van Seventer GA, Levin SM, Wright SD. Two leukocyte receptors (CD11a/CD18 and CD11b/CD18) 
mediate transient adhesion to endothelium by binding to different ligands. J Immunol 1989; 143: 33253329.

78. Benlacqua MP, Stengelin S, Gimbrone MA, Seed B. Endothelial leukocyte adhesion molecule 1: an inducible receptor for neutrophils related to complement regulatory proteins and lectins. Science 1989; 243: 1160-1165.

79. Di Stefano A, Maestrelli P, Roggeri A, et al. Upregulation of adhesion molecules in the bronchial mucosa of subjects with chronic obstructive bronchitis. Am J Respir Crit Care Med 1994; 149: 803-810.

80. Cox G, Gauldie J, Jordana M. Bronchial epithelial cellderived cytokines (G-CSF and GM-CSF) promote the survival of peripheral blood neutrophils in vitro. Am J Respir Cell Mol Biol 1992; 7: 507-513.

81. Eidelman D, Saetta MP, Ghezzo H, et al. Cellularity of the alveolar walls in smokers and its relation to alveolar destruction. Functional implications. Am Rev Respir Dis 1990; 141: 1547-1552.

82. Wright JL. Airway inflammatory cells in upper and lower lobes in lungs of patients with and without emphysema. Pathol Res Pract 1988; 183: 297-300.

83. Fournier M, Lebargy F, Le Roy Ladurie F, Lenormand $\mathrm{E}$, Pariente R. Intraepithelial T-lymphocyte subsets in the airways of normal subjects and of patients with chronic bronchitis. Am Rev Respir Dis 1989; 140: 737742.

84. Saetta M, Di Stefano A, Maestrelli P, et al. Activated T-lymphocytes and macrophages in bronchial mucosa of subjects with chronic bronchitis. Am Rev Respir Dis 1993; 147: 301-306.

85. Ginns C, Goldenheim PD, Miller LG, et al. T-lymphocyte subsets in smoking and lung cancer. Analysis by monoclonal antibodies and flow cytometry. Am Rev Respir Dis 1982; 126: 265-269.

86. Miller LG, Goldstein G, Murphy M, Ginns LC. Reversible alterations in immunoregulatory T-cells in smoking. Chest 1982; 82: 526-529.

87. Tollerud PJ, Clark JW, Brown LM, et al. Association of cigarette smoking with decreased numbers of circulating natural killer cells. Am Rev Respir Dis 1989; 139: 194-198.

88. Takeuchi M, Nagai S, Izumi T. Effect of smoking on natural killer cell activity in the lung. Chest 1988; 94 : 688-693.

89. Costabel U, Bross KJ, Reuter C, Rühle K-H, Matthys $\mathrm{H}$. Alterations in immunoregulatory $\mathrm{T}$-cell subsets in cigarette smokers. A phenotypic analysis of bronchoalveolar and blood lymphocytes. Chest 1986; 90: 39-44.

90. Leung DYM, Geha RS. Regulation of the human IgE antibody response. Int Rev Immunol 1987; 2: 75-91.

91. Kay AB. "Helper" (DC4+) T-cells and eosinophils in allergy and asthma. Am Rev Respir Dis 1992; 143: S22-S26.

92. Breit SN, Robinson JP, Luckhurst E. et al. Immunoregulation by alpha -antitrypsin. J Clin Lab Immunol 1982; 7: 127-131.
93. Breit SN, Luckhurst E, Penny R. The effect of alpha ${ }_{1}$ antitrypsin on the proliferative response of human peripheral blood lymphocytes. J Immunol 1983; 130: 681-688.

94. Ades EW, Hinson A, Chapuis-Cellier C, Arnaud P. Modulation of the immune response by plasma protease inhibitors. I. Alpha $a_{2}$-macroglobulin and alpha -antitrypsin inhibit natural killing and antibody-dependent cellmediated cytotoxicity. Scand J Immunol 1982; 15: 109-113.

95. Redelman D, Hudig D. The mechanism of cell-mediated cytotoxicity. I. Killing by murine T-lymphocytes requires cell surface thiols and activated proteases. $J$ Immunol 1980; 124: 870-878.

96. Hudig D, Haverty $\mathrm{T}$, Fulcher $\mathrm{C}$, et al. Inhibition of human natural cytotoxicity by macromolecular antiproteases. J Immunol 1981; 126: 1569-1574.

97. Finkelstein R, Ghezzo H, Cosio MG. Alveolar inflammation in smokers. Clin Invest Med 1993; 16: B122.

98. Wright JL, Wiggs BJ, Hogg JC. Airway disease in upper and lower lobes in lungs of patients with and without emphysema. Thorax 1984; 39: 282-285.

99. Petty TL, Silvers GW, Stanford RE, Baird MD, Mitchell RS. Small airway pathology is related to increased closing capacity and abnormal slope of phase III in excised human lungs. Am Rev Respir Dis 1980; 121: 449-456.

100. Cosio MG, Ghezzo H, Hogg JC, Paré P. Airway reactivity in smokers and its relation with emphysema type. Am Rev Respir Dis 1992; 145: A379.

101. Bosken CH, Wiggs BR, Paré PD, Hogg JC. Small airway dimensions in smokers with obstruction to airflow. Am Rev Respir Dis 1990; 142: 563-570.

102. Moreno RH, Hogg JC, Paré PD. Mechanics of airway narrowing. Am Rev Respir Dis 1986; 133: 11711180.

103. Gunst SJ, Warner DO, Wilson TA, Hyatt RE. Parenchymal interdependence and airway response to methacholine in excised dog lobes. J Appl Physiol 1988; 65: 2490-2497.

104. Macklem PT. Factors determining bronchial smooth muscle shortening. Am Rev Respir Dis 1991; 143: S47-S48.

105. Anderson AE, Foraker AG. Relative dimensions of bronchioles and parenchymal spaces in lungs from normal subjects and emphysematous patients. Am J Med 1962; 32: 218-226.

106. Saetta M, Ghezzo H, Kim WD, et al. Loss of alveolar attachments in smokers. A morphometric correlate of lung function impairment. Am Rev Respir Dis 1985; 132: 894-900.

107. Petty TL, Silvers GW, Stanford RE. Radial traction and small airways disease in excised human lungs. Am Rev Respir Dis 1986; 133: 132-135.

108. Nagai A, Yamawaki I, Takizawa T, Thurlbeck WM. Alveolar attachments in emphysema of human lungs. Am Rev Respir Dis 1991; 144: 888-891. 